Seismicity of the Earth 1900-2013

\section{East African Rift}

Compiled by Gavin P. Hayes,' Eric S. Jones,'Timothy J. Stadler,'William D. Barnhart' 2014 . 20 McNamara,' Harley M. Benz,' Kevin P. Furlong,' and Antonio Villaseñor'

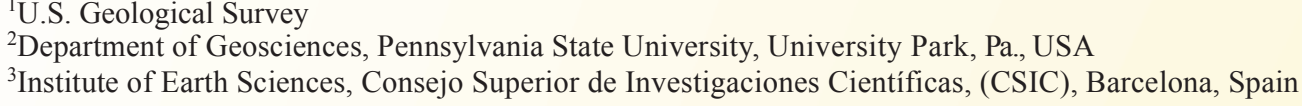

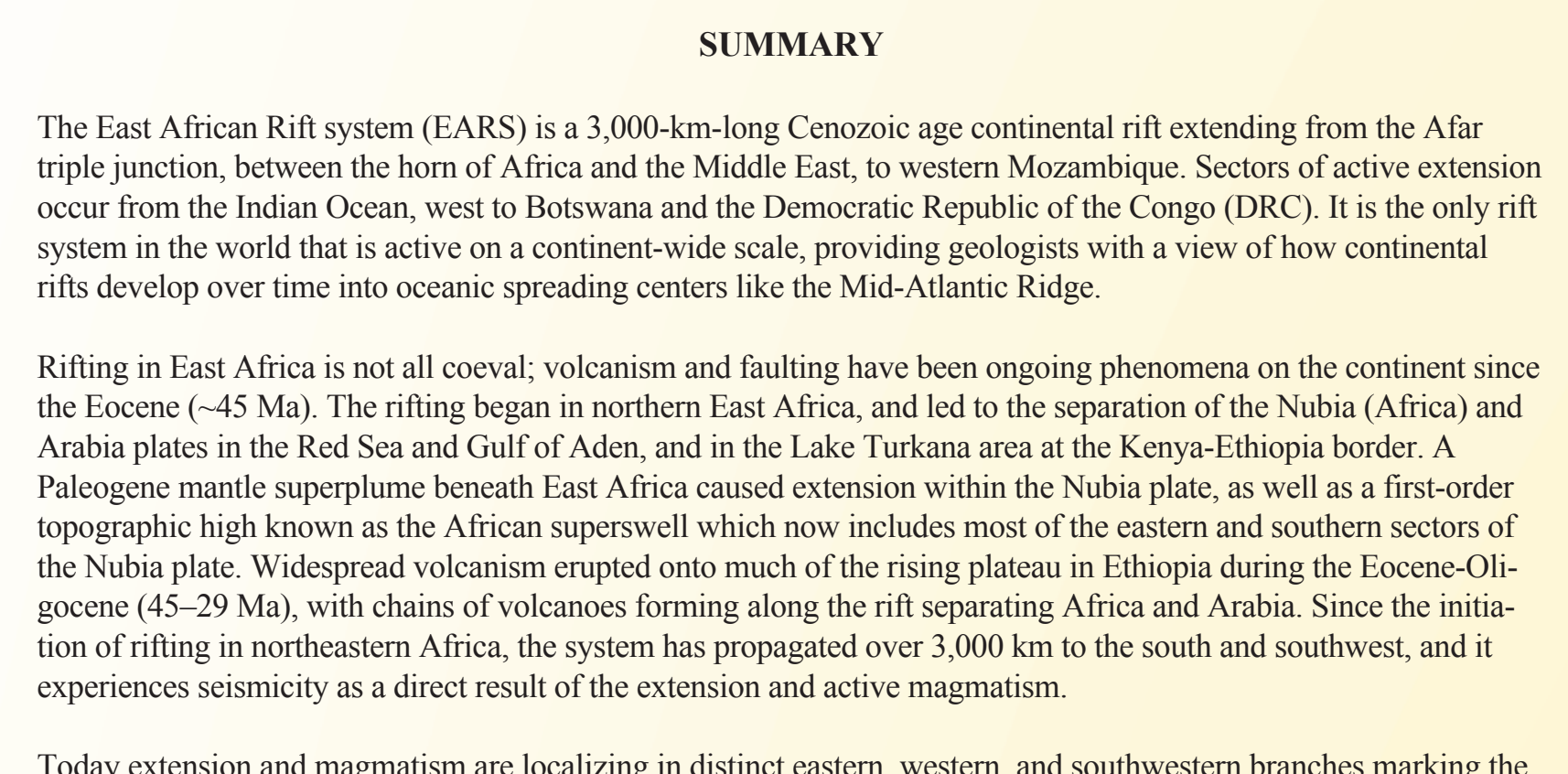

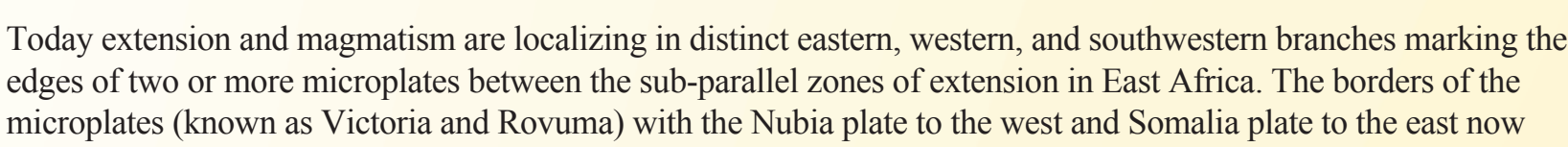

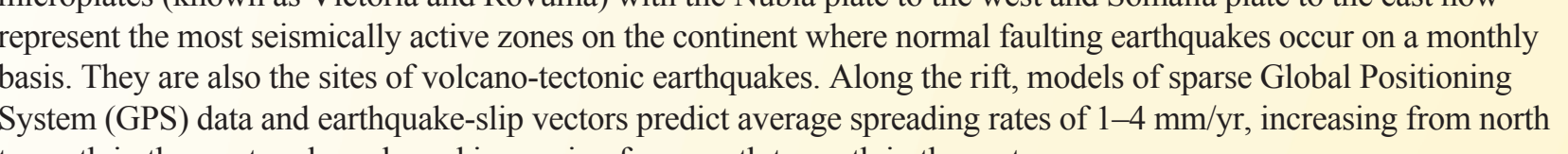

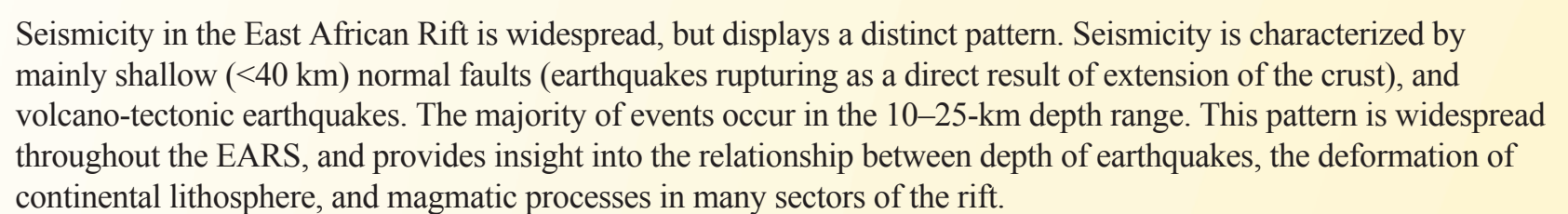

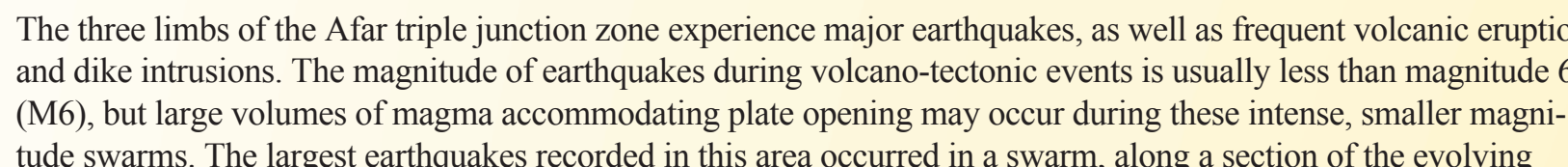

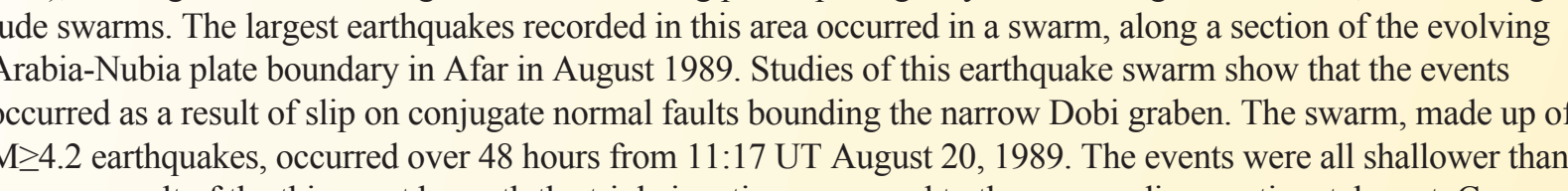

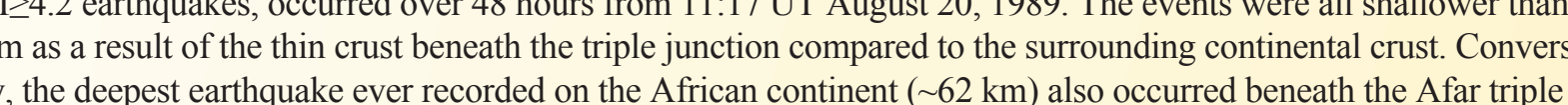

probably yssociated with the movement of magma at depph during hiter riting episiode.

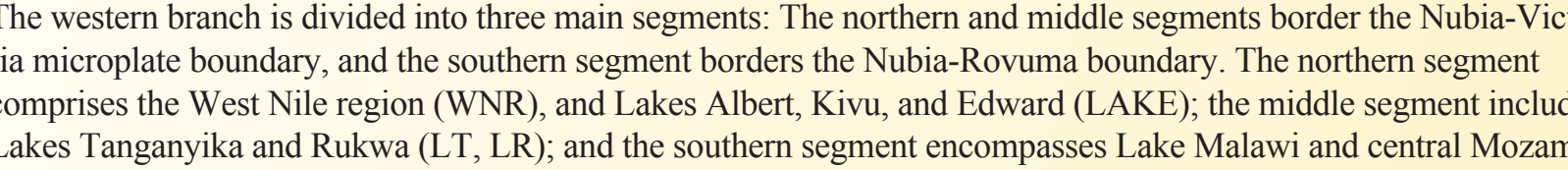

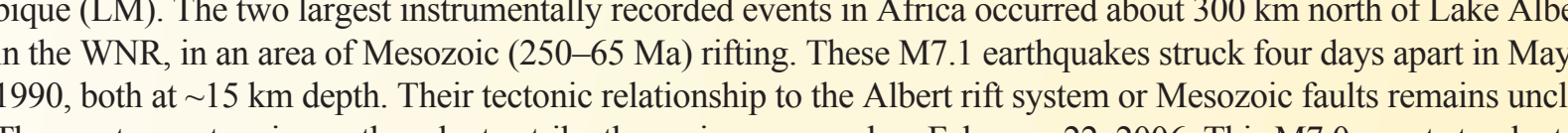

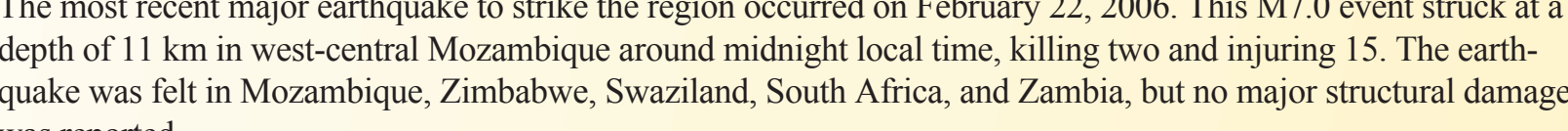

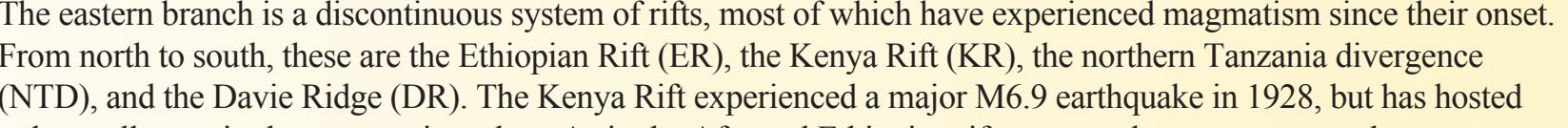

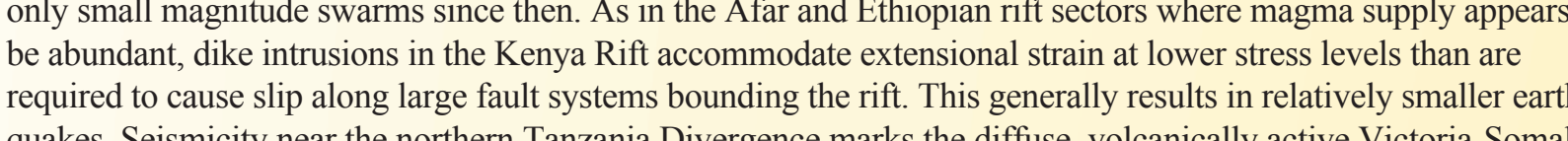

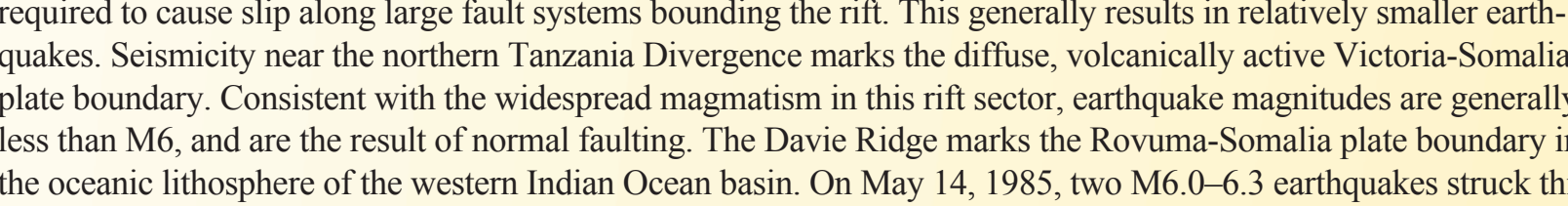

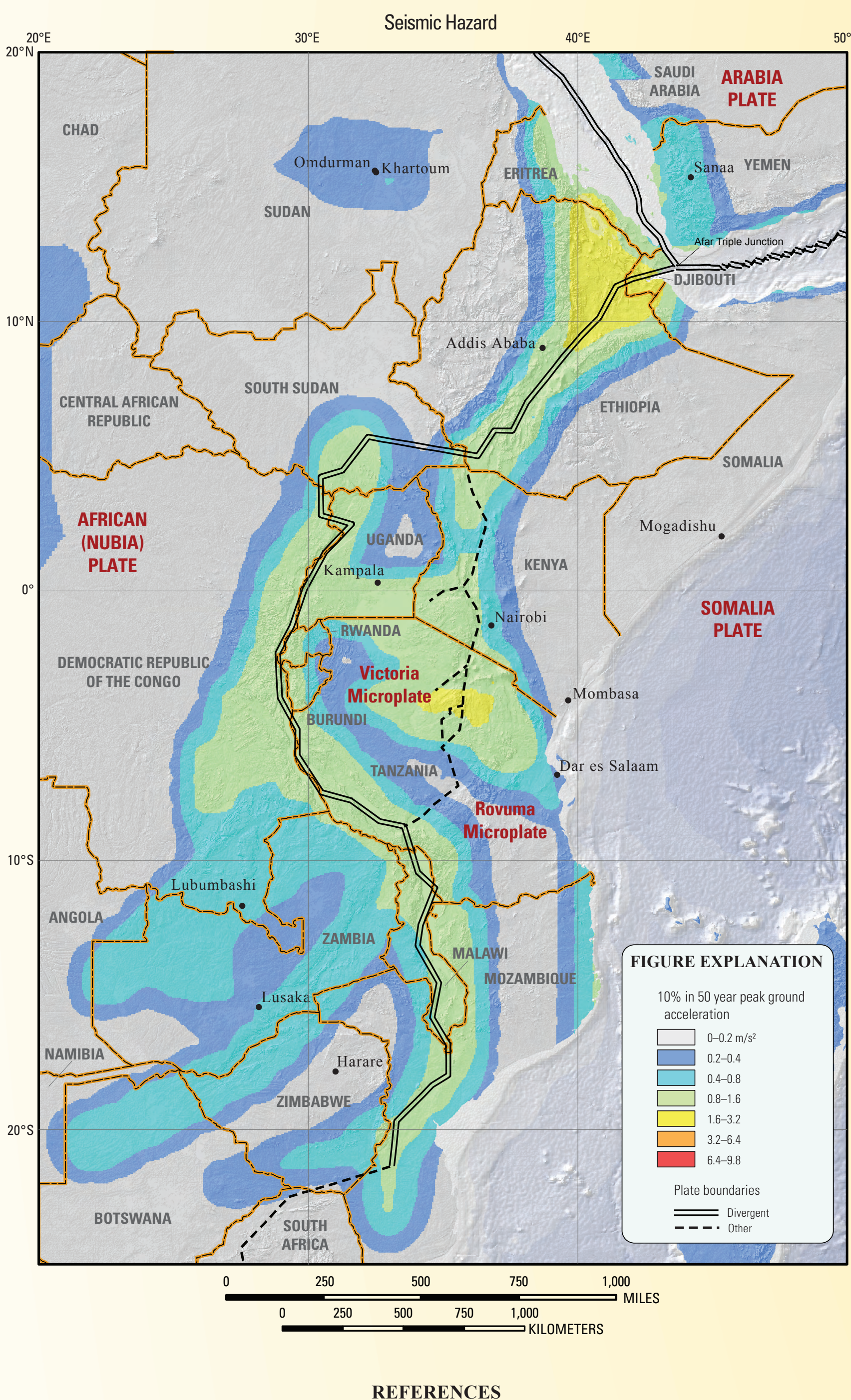

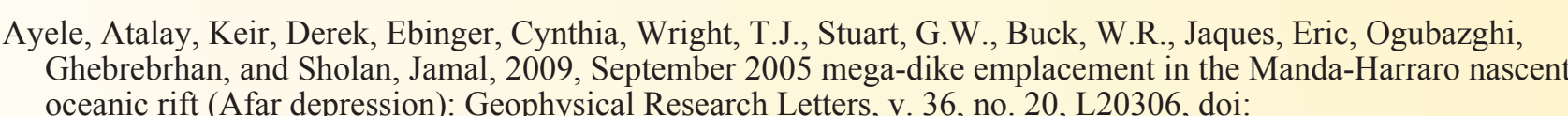

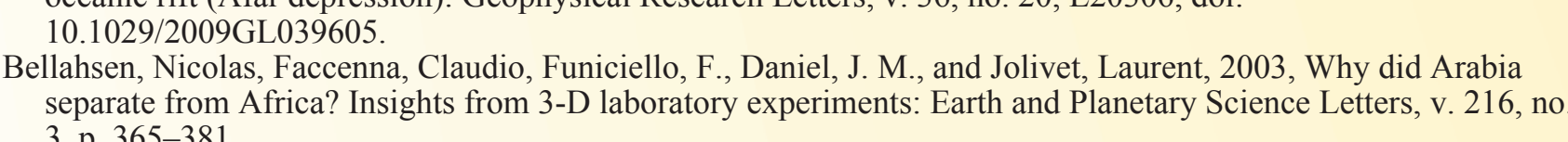

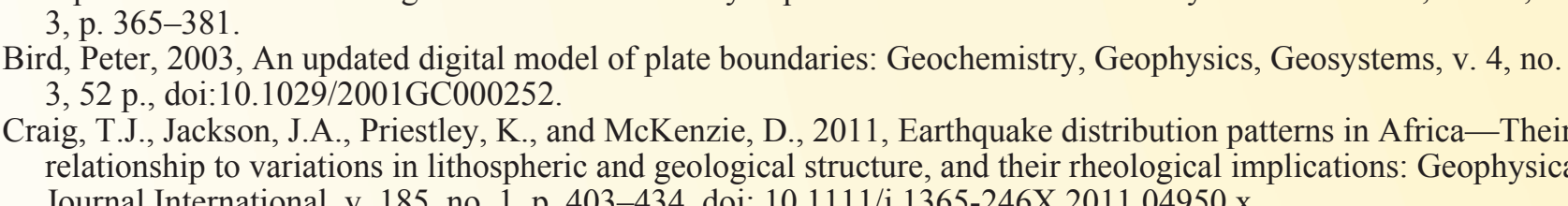

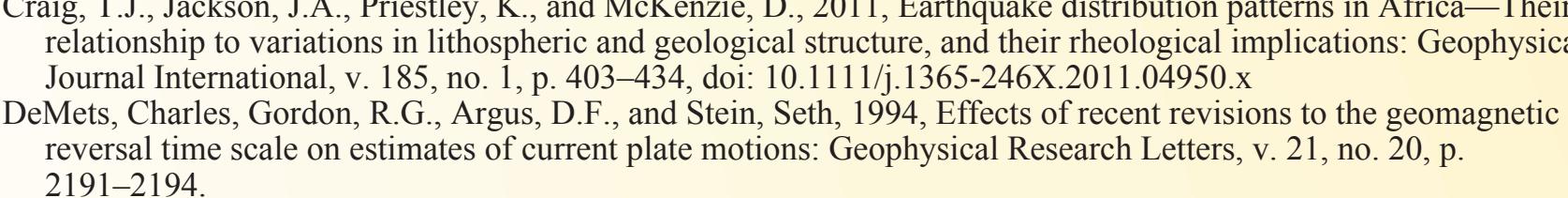

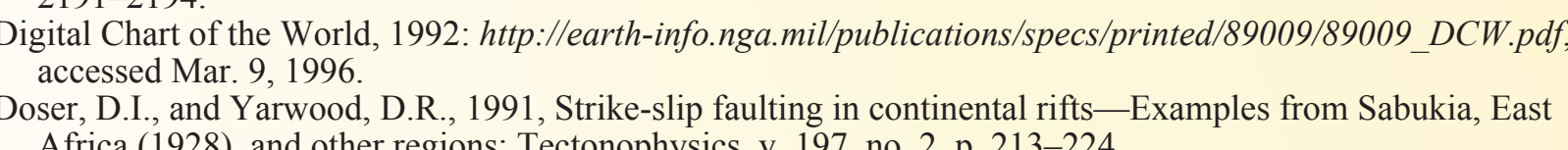

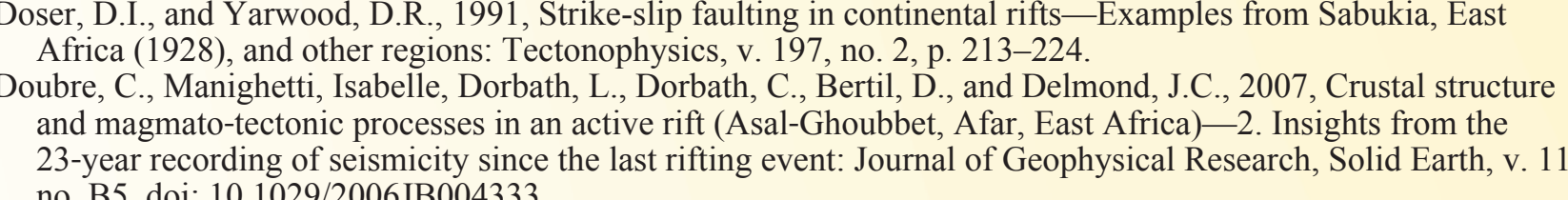

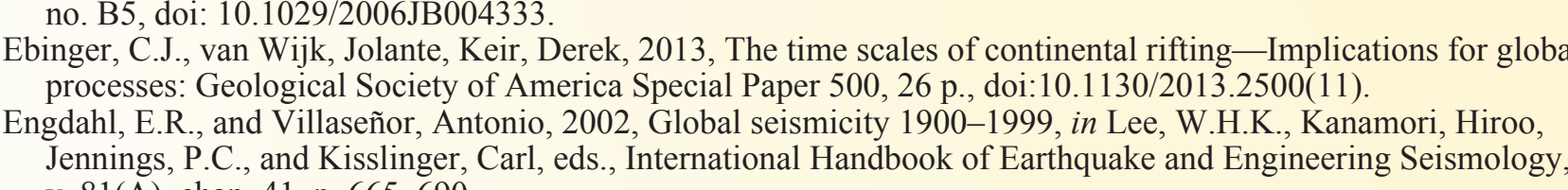

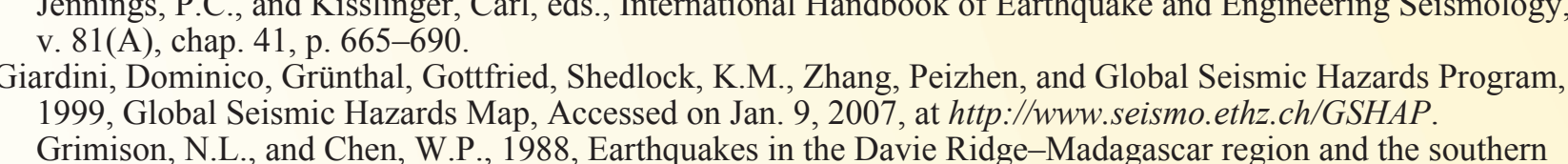

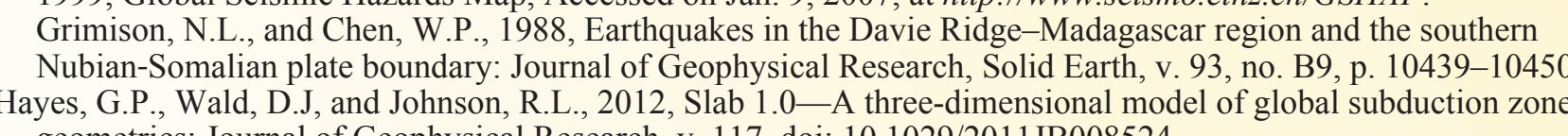

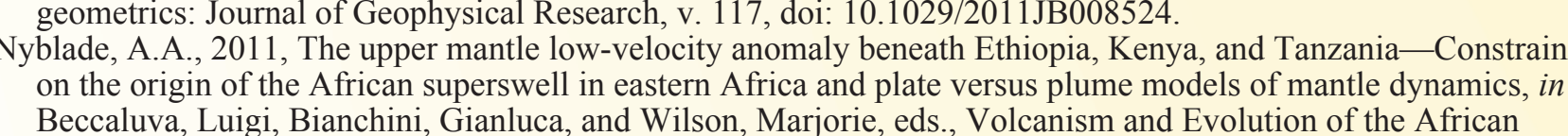

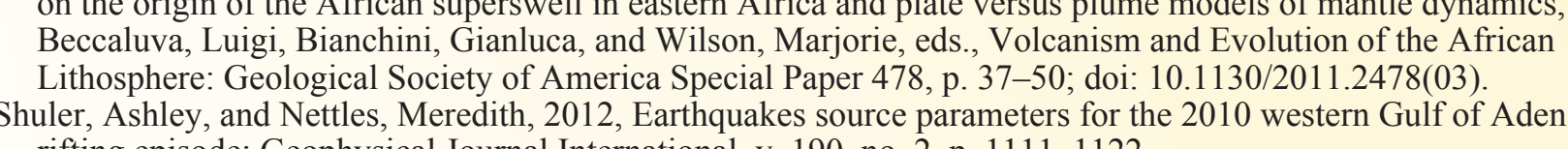

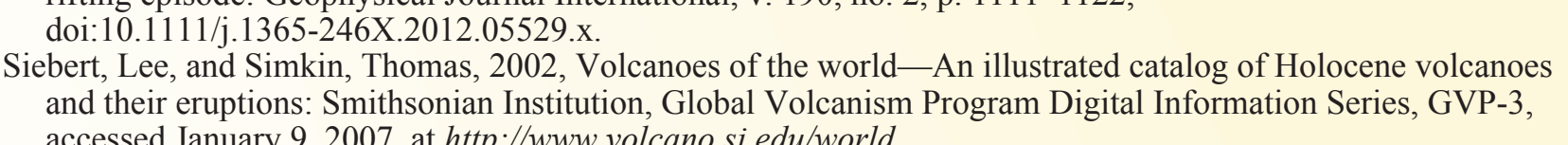

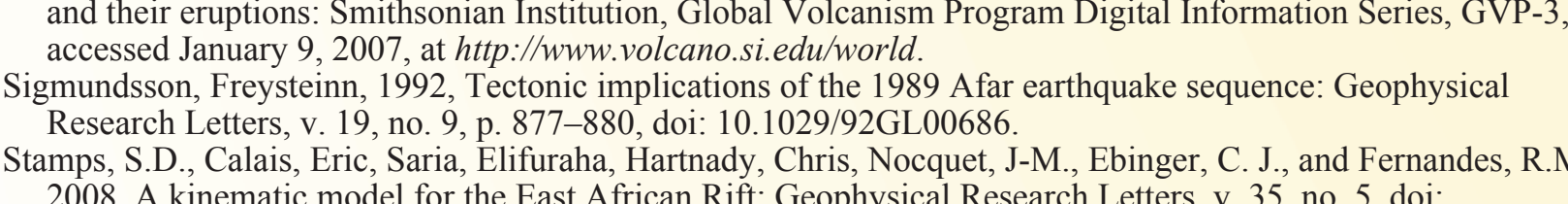

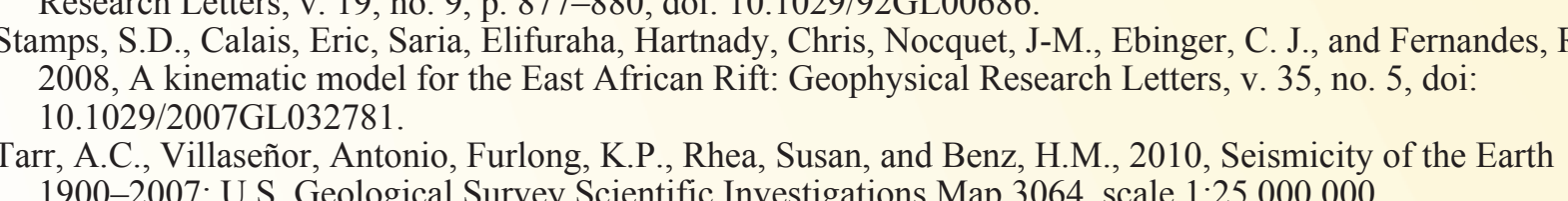

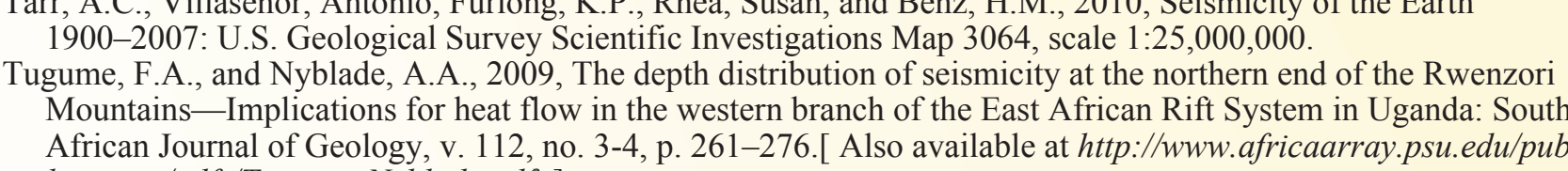

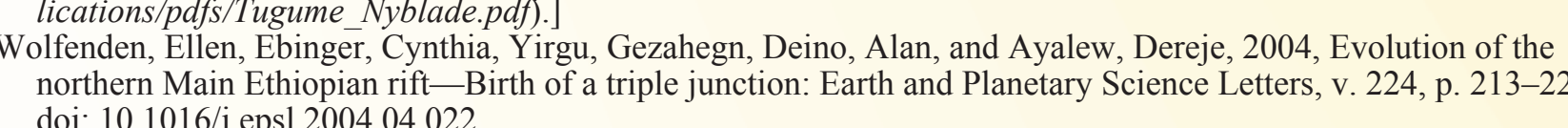

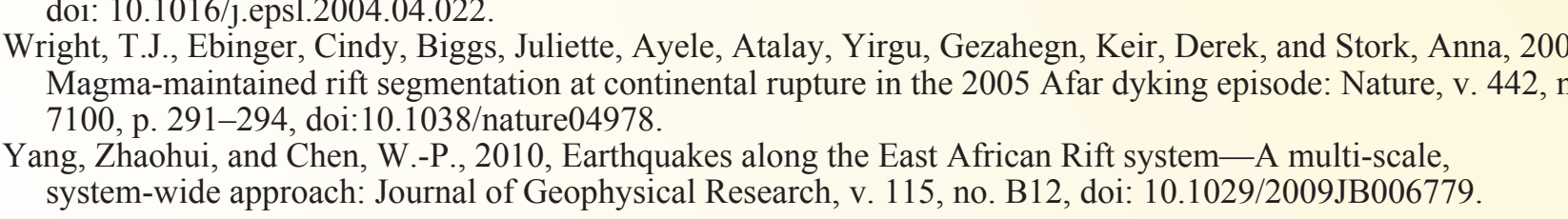

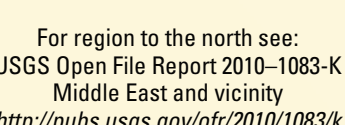

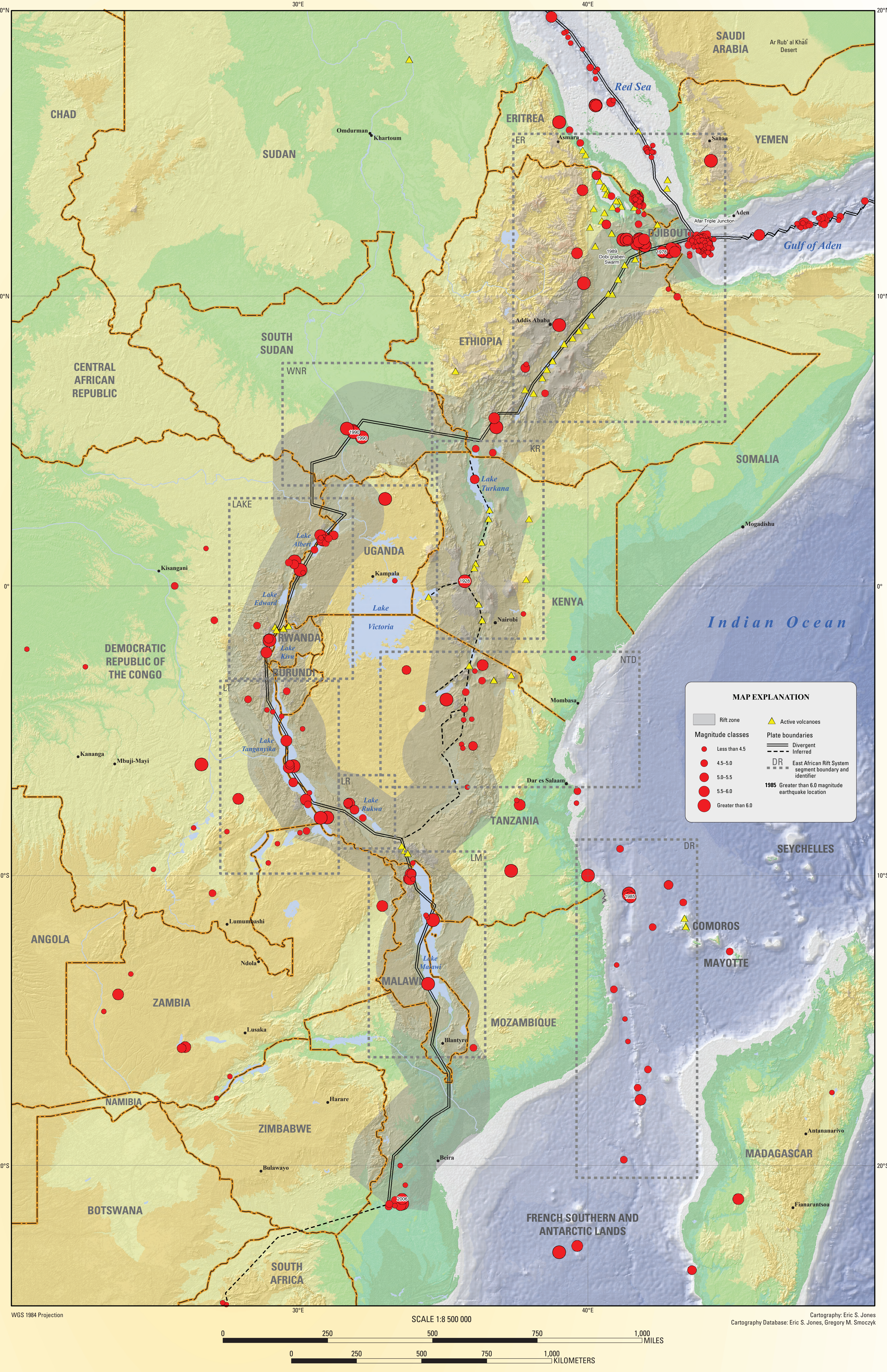

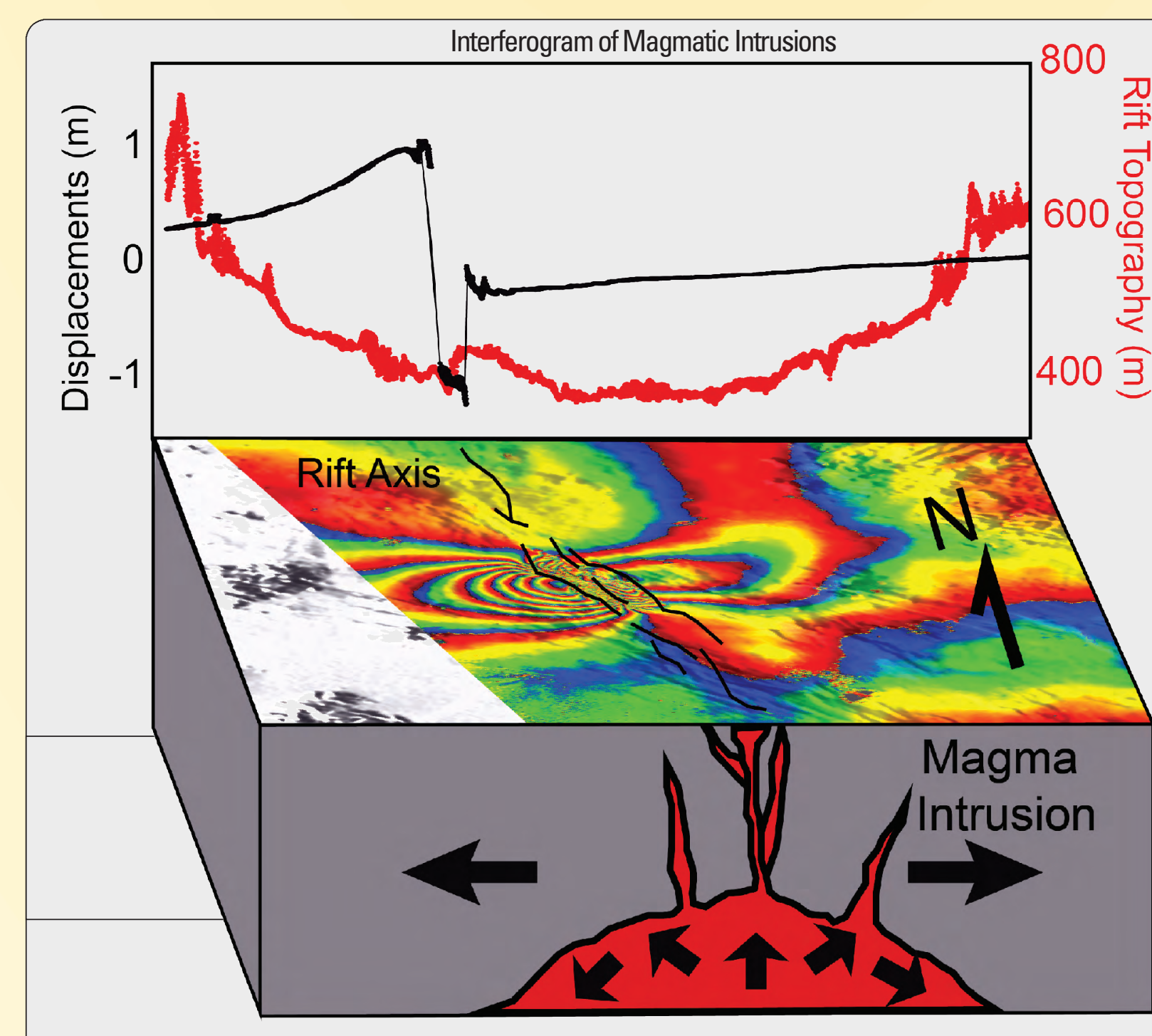

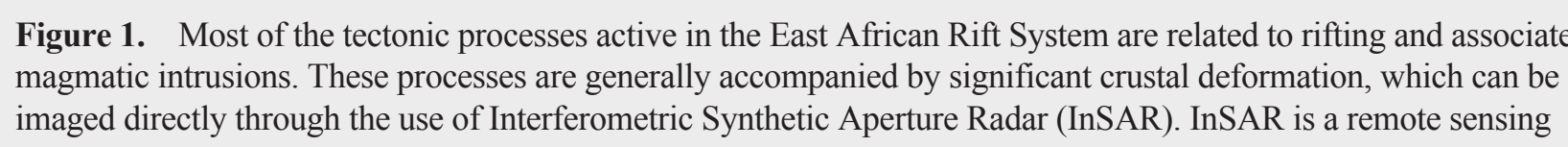

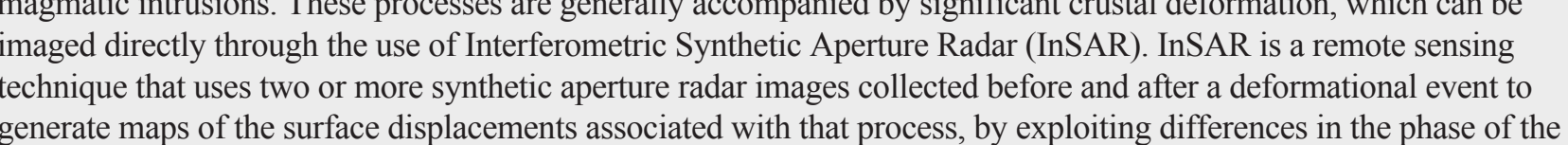

Fith
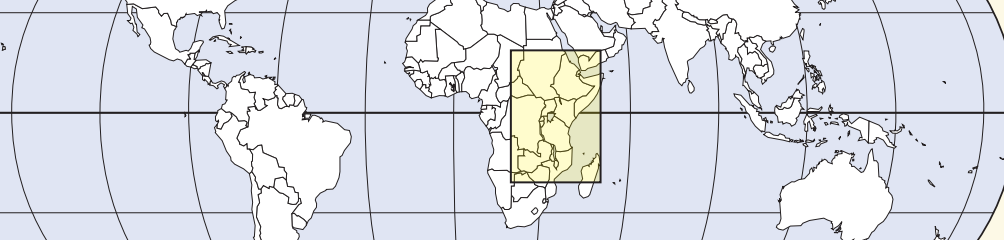

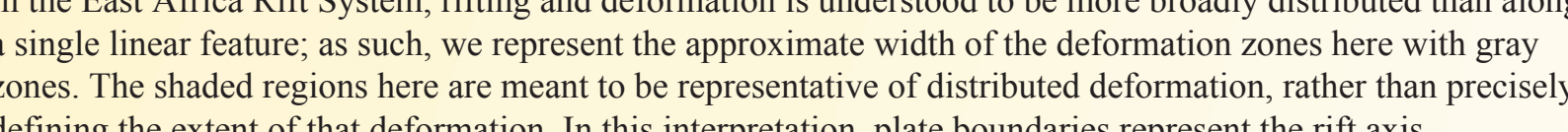

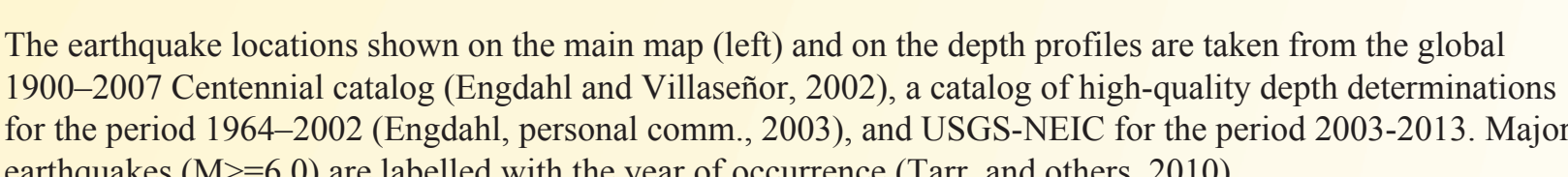

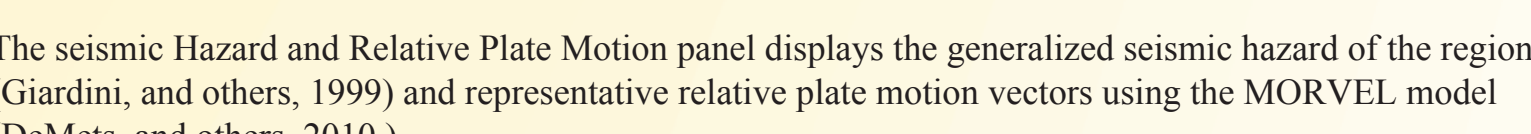

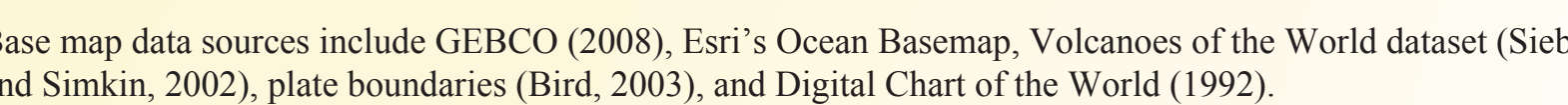

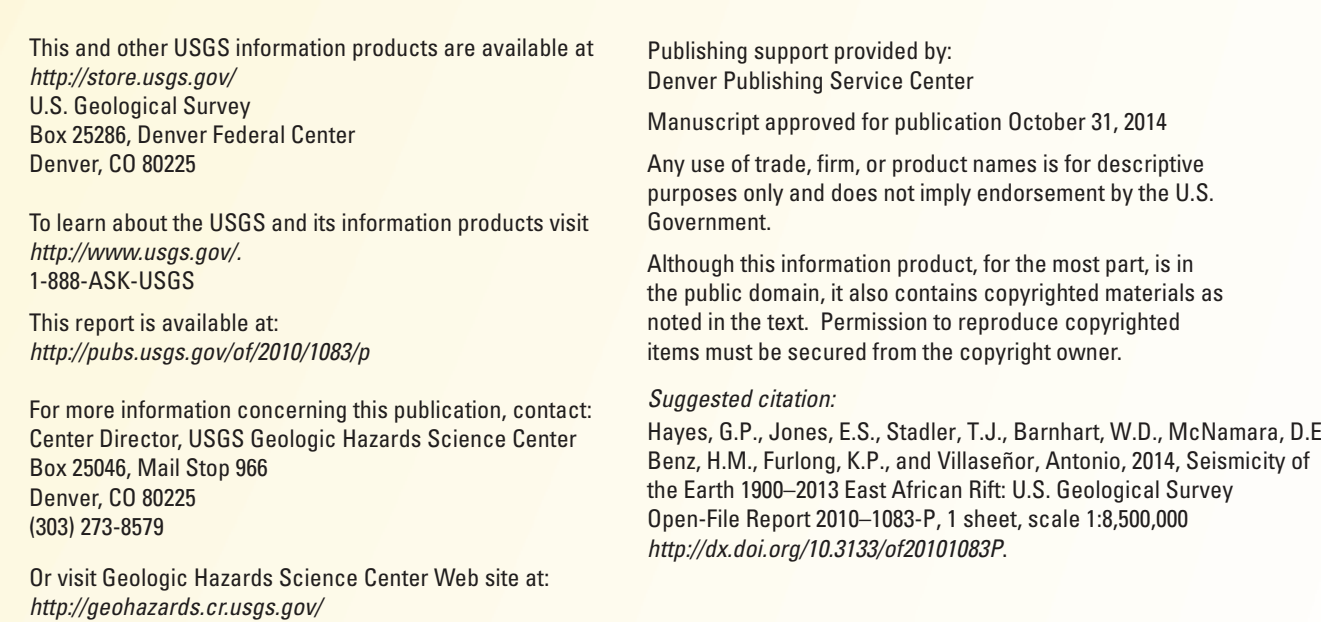

